\title{
A journey to soul-touching research in social sciences and humanities
}

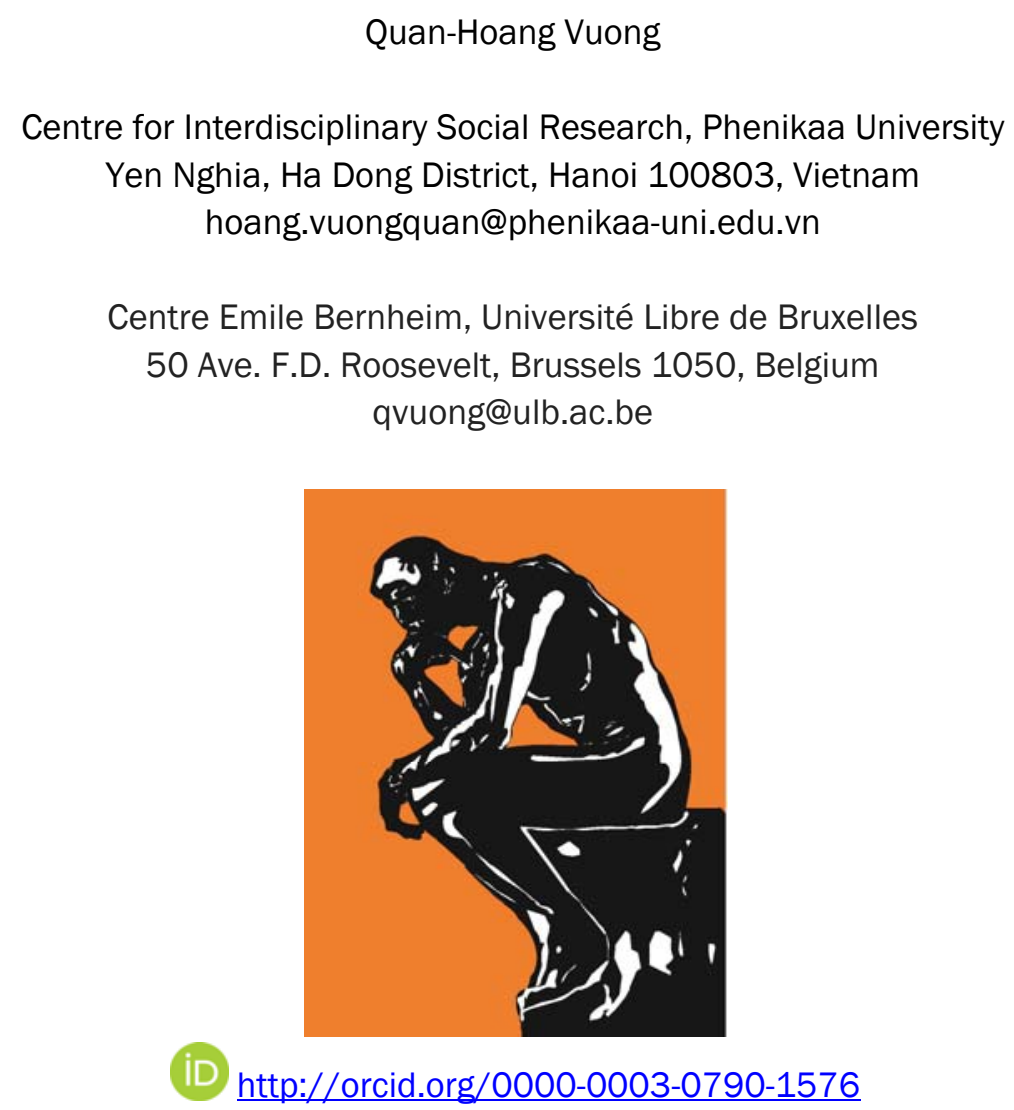

This draft v6; March 3, 2020 (un-peer-reviewed)

\section{Introduction}

The ancient city of Megiddo likely conjures in us no images or geographical connection, yet this 7,000year-old site in Israel is where the biblical legend of Armageddon - the last battle between the good and evil before the Day of Judgement - sprouted and fed our imagination of a lost great civilization or some historic battles. When I read a recent story about the decades-long excavation efforts at Megiddo [1], I was struck by the image that, perhaps when Alexander the Great marched through this city, all of its historical significance had faded into oblivion. As a social scientist, this made me ponder about the fate of our academic journey: if an ancient fallen city is remembered even just by a few short biblical descriptions of its greatness, are we capable of conducting research with the same memorability?

We researchers in the humanities and social sciences, similar to the archaeologists but only less literally, are constantly digging through unknown dirt and even uncharted territories in hopes of finding "diamonds." Clearly, the search for self-actualization or self-empowerment is inherent in every researcher even as he or she may have started out in academia with the most mundane goal of publishing as many articles as possible. This process is arduous and time-consuming. In this essay, I share some reflections on my own such journey, one that I would call the quest for soul-touching research. 


\section{Three principles}

\section{Principle no. 1: the 'soul factor'}

One of the first things to remember is, none of us is alone in this quest. As I looked back upon how the search for my self-defined "soul-touching" research took shape, I recalled a piece of advice (and encouragement) from my colleague, Prof. Nancy K. Napier, of Boise State University [2]. In an email sent to me last year, she had written: "It [the soul factor] is absolutely the right reason to do hard work."

This "soul factor" is not an abstraction; it is about meeting at least three out of the following four criteria: (i) doing good work, (ii) learning a lot, (iii) working with good people, and (iv) having fun. The factor, as Prof. Napier and I agree, emphasizes the importance of good teamwork, of doing research with good people, and helping real people. For my colleague, with her $40+$ years of research experience, projects that "touched her soul" were those that have genuine impacts, rather than just scoring points in academia.

\section{Principle no. 2: 'mindsponge'}

Getting started is one thing, but churning out interesting research ideas is another. From my own experience, to overcome this struggle, one needs to learn to filter and process information in a multifaceted manner. This is what Prof. Napier and I call the "mindsponge mechanism" [3], which is concerned with creating flexible ways of thinking and working more delicately. Its modus operandi requires socio-cultural adaptation and tolerance to emerging and strange sets of values.

The principle, which was developed out of the need to address acculturation challenges in the age of globalization, carries concrete implications for us researchers in the social sciences and humanities. To expand our mindsets, and subsequently attain innovations in our research projects, we need to improve our ability to observe, adapt, and integrate new values with our existing core values.

\section{Principle no. 3: serendipity}

Once the "mindsponge process" works, it lends support to our third principle-the concept of "serendipity as a strategic advantage" [4]. Both concepts were important for me to break the barriers in identifying research ideas. Appreciating their value is one thing, but practicing them is a whole lot different story because it can be a difficult task at times.

But their value should be made clear right here.

Serendipity, which is the ability to notice and act on opportunities others may miss, can serve as an important method for observing and noticing valuable research ideas. In this fast-moving world, some ideas may appear in a very short time--following news flows--and then disappear also very quickly. Or, the ideas may be buried in a huge amount of newly arriving information and 'interesting' data. So that the ability to identify ideas that others may not is crucial.

\section{The soul-touching research: Reflections on my experiences}

It is not easy for a researcher in the humanities and social sciences to choose which of her/his works can be considered the most important. But the quest for research pinnacles will still continue for 
those who want to advance and make meaningful contributions and seek to create impact (not impact factor!).

For me, it can be a manifestation of a journey to find soul-touching research. The searching process can help me answer such questions as: Who am I? Why was I born? What am I meant to do with my time? What is beautiful and valuable in my mind? What values can even transcend lifetimes?

'Normal' research projects tend to focus on data and techniques. Large datasets and fancy techniques with terrifying complexities are researchers' usual obsession. The researchers are under pressure, either self-imposed or from a "publish or perish" university climate, to produce striking results and impressive work that is acceptable to busy editors and precarious reviewers. For these research projects, it is understandable that researchers tend to forget the 'soul factor' since they believe that what editors and reviewers think is of higher importance and relevance.

However, the 'soul factor' is exactly what divides the world of research into the mediocre (including the good-looking and useless) and the great.

Undertaking great work demands time, energy, perseverance (following repeated failures), and can affect the researcher's health. Economic concerns (e.g., cost-benefit analysis, optimal use of time, or the like) are non-existent when researchers pursue soul-touching projects.

For me, three such projects manifest a soul touching research journey.

\section{Case no. 1: "Probabilities of destitution" have real faces}

As scientists, we may get tangled up in our own data and statistics, sometimes falsely putting the emphasis on a certain statistical significance test than on the real subjects involved in the test themselves. This misguided obsession not only takes away the "soul factor" of the research but also a researcher's own soul if I dare say.

In a research project conducted in 2014 on the risk of Vietnamese patients falling into destitution because of financial burdens [5], I spent hours getting to know the real faces and profiles of people affected by the shortfalls in government health care policies as well as their own limited economic conditions in case of sickness. The documented patient Nguyen Thi Lan (in a small commune in the southern Kien Giang province) was just one of countless examples about families undergoing financial hardships when one member got sick. As I came face-to-face with real patients whose health withered away and lived poorer each day, pieces of my heart broke.

Researchers are so often intently focused on collecting as many surveys as possible that getting one's heart and soul out there to connect with and understand the respondents seems like the very last thing. This is not to say that the surveys were emotionally-driven, and hence, subject to emotional biases. My point is, to have soul-touching research, we as researchers should be able to resonate with the real individuals in our projects. For me, I was able to identify factors conventionally overlooked in this kind of research. For instance, low-income patients with serious conditions are unlikely to give high amounts of "thank-you money"-which may be a cultural norm in Vietnam-because they are already paying for high treatment costs and unaccountable out-of-pocket payments at the hospitals.

It is in this project that my outlook on healthcare research got expanded and re-examined, giving rise to new ideas-precisely showing the "mindsponge process" and "serendipity" at work. 
Case no. 2: Ancient stories, like the "Lost City of Solomon," once unearthed properly can be empowering

A second project yielded the publication of an article on Three Teachings (Confucianism, Taoism, and Buddhism) and religious values in ages-old folktales [6]. And it didn't materialize out of a vacuum. Three hours for conceiving the main ideas while having coffee on a Lunar New Year holiday in 2018. Two weeks of preparing data. One week of statistical analysis, including computer code writing. Three more weeks for writing the first draft, and finally about four months for submitting and revising the manuscript before editorial acceptance. The problem with this counting job is that at least two critically important elements go missing.

The research ideas came from three people who were all near 50 by the time they conceived the value of life, and all three have been deeply influenced by folktales in their childhoods. The 'permanent bank' of the memory served them well and activated the serendipity mechanism.

How the ideas percolated in this case strongly depended upon how comfortable one was with letting values of statistical measures permeate through the layers of religious details and teachings. The "mindsponge process" also works the other round: Making it possible for religious teaching and folktale details to be quantified in an analyzable way.

Without these two elements, the research process could not have even started.

\section{Case no. 3: When art meets data science...}

In 2019, as we lamented about the poor conservation of historic architecture around Hanoi, we had a strange idea of learning about cultural evolution by using photos of old houses in Hanoi downtown [7].

Our coauthor Bui Quang Khiem began taking photos in 2012. I accompanied him on another Lunar New Year holiday in 2017, taking photos of some old streets. The project made its debut in September 2018, when we saw the light emitted from performing some innovative data modeling.

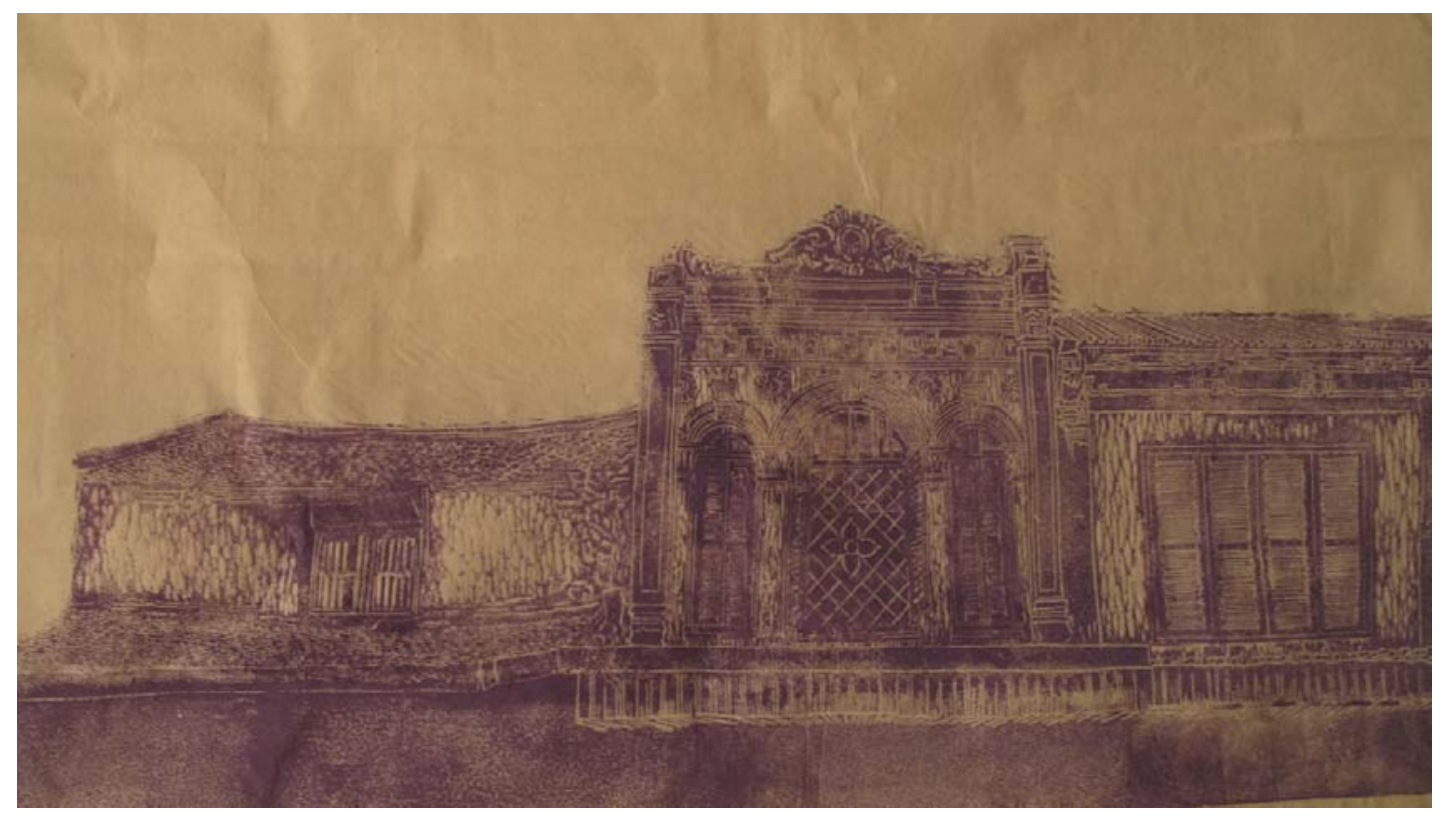

Figure 1. A linocut painting by Bui Quang Khiem examined during the undertaking of [7] 
During the undertaking, we even had to write a new computer package using the $\mathrm{R}$ language for about four months [8]. It is the same serendipity mechanism that has led us to stumble on an opportunity of making a new type of academic contribution: computing and graphics software package in R. Also, collecting data required us to write a web-based program that enabled respondents to evaluate the photos.

For me, this project epitomizes the seamless working of both the serendipity and mindsponge concepts.

\section{A final remark}

One thing I learned in my journey is that we cannot stop the soul-touching research once it starts. Regardless of its costliness, whether to our health or savings, the pursuit is soul-sustaining and worthwhile. Sharing the principles and my own experiences, I hope to facilitate a dialogue beyond the prevalent "publish or perish" one.

Conducting research is like having a conversation with the world, trying to make sense of the world to ourselves and others. For the sake of the conversation, a researcher must develop an ability to feel one's soul resonated so deeply with something, which means to be exposed and challenged. I would like to end this essay with a note on vulnerability by the English poet David Whyte:

"To run from vulnerability is to run from the essence of our nature, the attempt to be invulnerable is the vain attempt to become something we are not and most especially, to close off our understanding of the grief of others. More seriously, in refusing our vulnerability, we refuse the help needed at every turn of our existence and immobilize the essential, tidal, and conversational foundations of our identity." [9]

\section{References}

[1] Robinson R. (2020). The archaeology of Armageddon. Nature 578:510-511. https://doi.org/ 10.1038/d41586-020-00510-w

[2] Napier NK. (2020). Nancy K. Napier [Internet]. Available from https://nancyknapier.com/ [Cited 2020 Mar 03]

[3] Vuong QH, Napier NK. (2015). Acculturation and global mindsponge: an emerging market perspective. International Journal of Intercultural Relations 49:354-367. https://doi.org/10.1016/j.ijintrel.2015.06.003

[4] Napier NK, Vuong QH. (2013). Serendipity as a strategic advantage?. In: Wilkinson T, editors. Strategic Management in the 21st Century. Westport, CT: Praeger/ABC-Clio; pp. 175-199.

[5] Vuong QH. (2015). Be rich or don't be sick: estimating Vietnamese patients' risk of falling into destitution. Springerplus 4:529. https://doi.org/10.1186/s40064-015-1279-x

[6] Vuong QH, Bui QK, La VP et al. (2018). Cultural additivity: behavioural insights from the interaction of Confucianism, Buddhism, and Taoism in folktales. Palgrave Communications 4:143. https://doi.org/10.1057/s41599-018-0189-2

[7] Vuong QH, Bui QK, La VP et al. (2019). Cultural evolution in Vietnam's early 20th century: A Bayesian networks analysis of Hanoi Franco-Chinese house designs. Social Sciences \& Humanities Open 1:100001. https://doi.org/10.1016/j.ssaho.2019.100001 
[8] La VP, Vuong QH. (2019). bayesvl: Visually Learning the Graphical Structure of Bayesian Networks and Performing MCMC with 'Stan'. The Comprehensive R Archive Network (CRAN). Available from https://cran.r-project.org/web/packages/bayesvl/index.html. [Cited 2020 Feb 03]

[9] Popova M. (2020). David Whyte on Vulnerability, Presence, and How We Enlarge Ourselves by Surrendering to the Uncontrollable. Brainpickings [Cited 2020 Feb 03]. Available from https://www.brainpickings.org/2016/04/11/david-whyte-vulnerability/ 